\title{
Экспресс-идентификация и определение натамицина в пищевых продуктах методом ультравысокоэффективной жидкостной хроматографии/квадруполь-времяпролетной масс-спектрометрии высокого разрешения
}

\author{
Большаков Д.С. ${ }^{1}$, Амелин В.Г. ${ }^{1,2}$ \\ ${ }^{1}$ Федеральныий цуентр охраны здоровья животных (ВНИИЗЖ), Владимир \\ ${ }^{2}$ Владимирский государственный университет имени Александра Григорьевича \\ и Николая Григорьевича Столетовых, Владимир
}

Поступила в редакцию 11.02.2019 г.

DOI: https://doi.org/10.17308/sorpchrom.2019.19/783

Предложена методика экспресс-идентификации и определения полиенового антибиотика натамицина в пищевых продуктах методом ультравысокоэффективной жидкостной хроматографии в сочетании с квадруполь-времяпролетной масс-спектрометрией высокого разрешения. Диапазон определяемых содержаний натамицина составил от 0.5 до 100 нг/г. Для определения обнаруженного натамицина предложено использовать метод стандартной добавки. Относительное стандартное отклонение результатов анализа не превышало 0.12. Продолжительность идентификации проб 20 мин, определения натамицина - 40 мин.

Ключевые слова: натамицин, пищевые продукты, ультравысокоэффективная жидкостная хроматография, квадруполь-времяпролетная масс-спектрометрия высокого разрешения.

\section{Express-identification and determination of natamycin in foodstuffs by method of ultra-high performance liquid chromatography/quadrupol-time-of-flight mass-spectrometry of high-resolution}

\author{
Bol'shakov D.S. ${ }^{1}$, AmelinV.G. ${ }^{1,2}$ \\ ${ }^{I}$ Federal Centre for Animals Health (ARRIAH), Vladimir \\ ${ }^{2}$ Vladimir State University named after Alexander and Nikolay Stoletovs, Vladimir
}

First of all, the method of rapid identification and determination of natamycin in food products (alcoholic and non-alcoholic beverages, cheese) by ultra-high-performance liquid chromatography in combination with quadrupole-time-of-flight mass spectrometry of high-resolution. For sample preparation, it was proposed to use liquid extraction with a mixture of deionized water and acetonitrile (for alcoholic and nonalcoholic beverages - dilution), followed by centrifugation. The optimal conditions for chromatographic separation were chosen: the composition of the mobile phases, the program of gradient elution, the column temperature, the volume of the injected sample (A) and $0.1 \%$ formic acid in acetonitrile (B). The optimal conditions for the gradient elution mode are as follows: $0 \mathrm{~min}-5 \% \mathrm{~B}, 0.5 \mathrm{~min}-5 \% \mathrm{~B}, 2 \mathrm{~min}-50 \% \mathrm{~B}, 5$ $\min -100 \% \mathrm{~B}, 6 \mathrm{~min}-5 \% \mathrm{~B}, 8 \mathrm{~min}-5 \% \mathrm{~B}$. The flow rate of the mobile phase was $0.4 \mathrm{ml} / \mathrm{min}$. The temperature of the column thermostat is $30^{\circ} \mathrm{C}$. The volume of the injected sample is $20 \mu$ l. The duration of the 
chromatographic separation was 8 minutes To assess the quantitative content of natamycin in food products used by standard additives, which has already proven itself in determining residual quantities of veterinary drugs in food products, feed and raw materials for their production. Under selected conditions of extraction, separation of extracts and mass spectrometric detection, several samples of the products were analyzed. Of the seven samples in one sample of fruit nectar, in one sample of wine and one sample of cheese (cortical layer), natamycin was found at the level of $15 \pm 3,18 \pm 3$ and $23 \pm 4 \mathrm{ng} / \mathrm{g}$ respectively. Natamycin was not detected in the three samples of fruit juice (less than $0.2 \mathrm{ng} / \mathrm{ml}$ ). The correctness of the analysis was verified by the «introduced-found» method with the addition of natamycin at the level of $50 \mathrm{ng} / \mathrm{g}$. The range of determined contents of natamycin was $0.5-100 \mathrm{ng} / \mathrm{ml}(\mathrm{ng} / \mathrm{g})$, the detection limit was $0.2 \mathrm{ng} / \mathrm{g}$ with a sample mass of $1.00 \mathrm{~g}$.

Keywords: natamycin, food products, ultrahigh-efficiency liquid chromatography, high-resolution quadrupole-time-of-flight mass spectrometry.

\section{Введение}

Натамицин относят к группе полиеновых антибиотиков (рис. 1), обладающих фунгистатическим эффектом. Препарат разрушает клеточные мембраны грибка, тем самым приводя его к гибели [1]. В пищевой промышленности натамицин используется как консервант Е 235 при производстве сыров и колбас. Кроме того, натамицин может применяться при обработке молочных и кисломолочных продуктов, плавленых сыров, кондитерских изделий, рыбопродуктов, вин, фруктовых соков и других товаров, подверженных влиянию плесени и дрожжей [2].

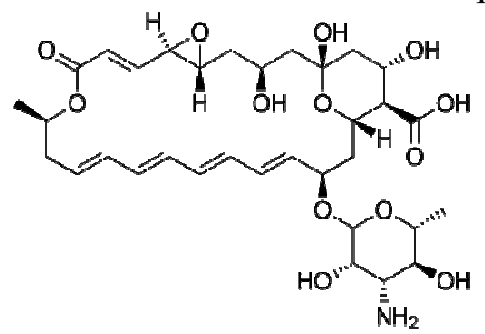

Рис. 1. Структурная формула натамицина.

Согласно международным нормам (Food and Agriculture Organization Expert Committee on Food Additives) максимальное ежедневное потребление натамицина не должно превышать 0.3 мг/кг веса, а допустимое содержание во фруктовых соках должно составлять 2 мг/дм ${ }^{3}$ готового товара. В список стран, на территории которых распространяется запрет на использование натамицина в вине входят США, Аргентина, Чили, Канада и Новая Зеландия, а также страны, входящие в состав Европейского союза (EC) [3, 4]. Однако в настоящее время пищевой консервант Е235 продолжают применять в процессе изготовления продуктов питания в странах ЕС, США, Японии, Канады, Азии, а также в Российской Федерации и в странах ближнего зарубежья [5].

Согласно Техническому регламенту Таможенного Союза «Требования безопасности пищевых добавок, ароматизаторов и технологических вспомогательных средств» (ТР ТС 029/2012) допускается использование натамицина для поверхностной обработки сыров, колбасы сырокопченой и полукопченой при предельно допустимом содержании консерванта 1 мг/дм² в слое глубиной до 5 мм [6].

Действующая в Российской Федерации нормативная документация [6,7] в настоящее время не регламентируют максимально допустимый уровень (МДУ) натамицина в алкогольной и соковой продукции. Однако, в соответствии с Технический регламентом Таможенного Союза «Технический регламент на соковую продукцию из фруктов и овощей» (ТР ТС 023/2011) консервирование сока может быть осуществлено только с использованием физических способов. Кроме того, натами- 
цин не входит в перечень пищевых добавок и технологических средств, разрешенных для использования при производстве соковой продукции из фруктов и (или) овощей [8]. Что говорит о недопустимости его использования при производстве соковой продукции из фруктов и овощей.

Самые высокие МДУ натамицина приняты в Китае [9], согласно которым содержание натамицина в ферментированных алкогольных напитках может достигать $0.01 г /$ дм $^{3}$.

Необходимость определения данного антибиотика в пищевой продукции обоснована тем, что его накопление в организме человека опасно развитием привыкания и резистентности. В связи с необходимостью контроля безопасности пищевой продукции, на сегодняшний день предложен ряд методик определения содержания натамицина. Так, для определения натамицина в молочной продукции используется метод высокоэффективной жидкостной хроматографии (ВЭЖХ) с диодно-матричным и УФ-детектированием [10-13]. Для сыров разработана методика спектрофотометрического определения натамицина [14], которая предполагает проведение жидкостной экстракции аналита метанолом и заморозку полученного экстракта для отделения жировой фазы продукта.

Для определения натамицина в вине предложено использовать метод ВЭЖХ с масс-спектрометрическим детектированием в сочетании с твердофазным экстракционным (ТФЭ) концентрированием пробы $[15,16]$ и метод капиллярного электрофореза (КЭ) [17]. Применение методов ВЭЖХ предполагает фильтрование аликвоты образца вина с дальнейшей очисткой пробы на патронах Oasis ${ }^{\circledR}$ HLB для устранения мешающего влияние компонентов матрицы. Установлено, что оптимальным является элюирование натамицина с сорбента картриджа 90-100 \% метанолом [15]. В качестве недостатка подобных методик следует указать использование дополнительных стадий подготовки пробы, что приводит к увеличению продолжительности и стоимости анализа, а также использование токсичных растворителей. При использовании метода КЭ подготовка образца вина заключается в фильтровании, разбавлении дистиллированной водой и центрифугировании пробы. При этом нижняя граница диапазона измерений массовой концентрации натамицина в винах составляет 0.2 мг/дм ${ }^{3}$. Для уменьшения предела определения натамицина возможно использовать дополнительную стадию концентрирования пробы (ТФЭ, увеличение времени и изменение способа ввода пробы). Недостатком данной методики является низкая концентрационная чувствительность методики и влияние мешающих компонентов матрицы при регистрации пика аналита [17].

Цель данной работы заключалась в разработке методики экспрессидентификации и определения натамицина в пищевых продуктах методом ультравысокоэффективной жидкостной хроматографии/квадруполь-времяпролетной масс-спектрометрии высокого разрешения.

\section{Эксперимент}

Аппаратура. Использовали ультравысокоэффективный жидкостной хроматограф UltiMate 3000 (Thermo Scientific, США) в сочетании с квадрупольвремяпролетным масс-спектрометрическим детектором maXis 4G и электрораспылительную ионизацию в устройстве ionBooster (Bruker Daltonics, Германия). Разделение проводили на колонке $30 \times 2.1$ мм (1.7 мкм) ACQUITY UPLC ${ }^{\circledR}$ BEN C18 (Thermo Scientific, США) в режиме градиентного элюирования.

Применяли весы аналитические Sartorius TE214S специального класса точности с пределом взвешивания 0.1 мг (Sartorius, Германия); весы лабораторные тех- 
нические Ohaus SPU-202 Scout Pro Balance с пределом взвешивания 0.01 г (Ohaus Corporation, CША); центрифугу MPW-260R (MPW Med. Instruments, Польша); центрифугу лабораторная медицинскую фирмы ОПН-3M (DASTAN, Россия); ультразвуковую баню ПСБ-ТАСС (ЭЛСИКО, Россия); микродозаторы «Biohit» с переменным объемом 10-100 мкл, 100-1000 мкл, 1000-5000 мкл и пределом допускаемой погрешности измерения не более $\pm 2 \%$; фильтры мембранные политетрафторэтиленовые 0.22 мкм, диаметром 25 мм (Corning Incorporated, Германия).

Реактивы. Использовали стандартный образец натамицина (Sigma-Aldrich, США) с содержанием основного вещества 95\%. Исходный стандартный раствор натамицина $\left(1 \mathrm{mг} / \mathrm{cm}^{3}\right)$ готовили растворением навески препарата в ацетонитриле. Рабочие растворы готовили разбавлением исходных деионированной водой (15-18 МОм·см², ТУ 2123-002-00213546-2004). Использовали ацетонитрил, изопропиловый спирт (Scharlab, S.L., Испания), муравьиную кислоту (Sigma-Aldrich, CША), формиат натрия (Fluka, CША).

Идентификация и определение. Идентификацию натамицина по полученным хроматограммам проводили с использованием программного продукта «DataAnalysis-4.1», «TargetAnalysis» (Bruker Daltonics, Германия), составление картины изотопного распределения аналитов - с использованием «IsotopePattern» (Bruker Daltonics, Германия). Неизвестную концентрацию аналита в пробе $\left(c_{x}\right)$ рассчитывали методом стандартной добавки по формуле:

$$
\mathrm{c}_{\mathrm{x}}=\mathrm{c}_{\text {доб }} /\left[\left(\mathrm{S}_{\mathrm{x}+\text { доб }} / \mathrm{S}_{\mathrm{x}}\right)-1\right] \text {, }
$$

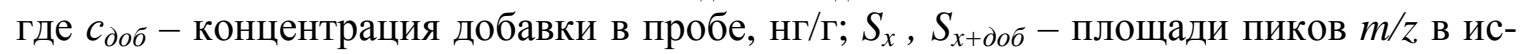
следуемом растворе и в растворе с добавкой аналита, соответственно.

Условия хроматографического разделения и детектирования. Подвижная фаза состояла из $0.1 \%$-ной муравьиной кислоты в воде (А) и $0.1 \%$-ной муравьиной кислоты в ацетонитриле (В). Хроматографирование проводили в градиентом режиме по следующей схеме: 0 мин - 5\% В, 0.5 мин - 5\% В, 2 мин - 50\% В, 5 мин $-100 \%$ В, 6 мин - 5\% В, 8 мин - 5\% В. Скорость потока подвижной фазы $0.4 \mathrm{~cm}^{3} /$ мин. Оптимальная температура хроматографической колонки $30{ }^{\circ} \mathrm{C}$, объем вводимой пробы 20 мкл.

Использовали электрораспылительную ионизацию в устройстве ionBooster (Bruker Daltonics, Германия). Установлены следующие оптимальные значения параметров ионизации: напряжение на щите капилляра 400 В, на капилляре 1000 В,

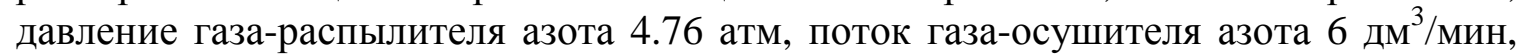
температура газа-осушителя азота $200^{\circ} \mathrm{C}$, поток газа-испарителя азота $250 \mathrm{дм}^{3} / \mathrm{q}$, температура газа-испарителя азота $250^{\circ} \mathrm{C}$. Диапазон регистрируемых масс ионов 100-500 Да. Для калибровки использовали раствор формиата натрия 10 мМ в смеси вода-изопропанол (1:1) в интервале хроматографирования 7.5-8 мин.

Пробоподготовка. Вино, сок. В две центрифужные пробирки емк. 15 см$^{3}$ отбирали $1 \mathrm{~cm}^{3}$ исследуемого образца, добавляли $4 \mathrm{~cm}^{3}$ деионированной воды. В одну пробирку вносили 0.5 нг стандартного раствора натамицина (50 мкл раствора с

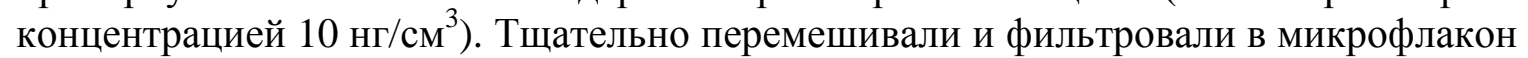
через мембранный фильтр 0.22 мкм. Полученные растворы хроматографировали.

Твердые продукты. В центрифужную пробирку емк. $15 \mathrm{~cm}^{3}$ вносили 1.00 г тщательно измельченного продукта, добавляли $1.0 \mathrm{~cm}^{3}$ деионированной воды и $4.0 \mathrm{~cm}^{3}$ ацетонитрила, встряхивали в течение 5 мин и центрифугировали при 2700 об/мин в течение 5 мин. Отбирали $1.0 \mathrm{~cm}^{3}$ экстракта, добавляли $1.0 \mathrm{~cm}^{3}$ деионированной воды, перемешивали и фильтровали в микрофлакон через мембранный фильтр 0.22 мкм. Полученный раствор хроматографировали. 


\section{Обсуждение результатов}

Оптимизация условий хроматографического разделения. Ряд предварительных исследований показал, что наиболее приемлемой является система подвижных фаз, состоящая из раствора $0.1 \%$-ной муравьиной кислоты в воде (ПФ А) и раствора $0.1 \%$-ной муравьиной кислоты в ацетонитриле (ПФ В). Такой состав ПФ позволил избавиться от значительных матричных помех, добиться наиболее приемлемой площади хроматографических пиков и оптимального времени удерживания определяемых соединений.

Установлено, что в качестве исходного соотношения ПФ А и В следует использовать отношение (95:5). В дальнейшем для увеличения элюирующей силы ПФ долю ацетонитрила увеличивали до $100 \%$, что также позволило существенно сократить время анализа.

Таким образом, оптимальные условия градиентного элюирования при определении натамицина следует представить следующим образом: 0 мин - 5\% ПФ В, 0.5 мин - 5\% ПФ В, 2 мин - 50\% ПФ В, 5 мин - 100\% ПФ В, 6 мин - 5\% ПФ В, 8 мин - 5\% ПФ В. Продолжительность хроматографического разделения составила 8 мин.

Для исследования влияния температуры была проведена серия экспериментов при значениях температуры термостата колонки от 20 до $60^{\circ} \mathrm{C}$ включительно, с шагом в $10^{\circ} \mathrm{C}$. Верхний предел выбирали из соображений стабильности неподвижной фазы. В результате было установлено, что площади и форма пиков существенным образом зависят от температуры. Наилучший результат был получен при проведении хроматографического разделения аналитов при температуре $30^{\circ} \mathrm{C}$.

Идентификация. Идентификацию натамицина проводили по полученным хроматограммам с использованием «TargetAnalysis-1.3.» (Bruker Daltonics, Германия), созданной базой данных (табл. 1) и идентификационным признакам. Обработку хроматограмм по общему ионному току и хроматограмм извлеченных масс ионов проводили с использованием «DataAnalysis-4.1» (Bruker Daltonics, Германия). Составление картины изотопного распределения аналитов проводили с использованием «IsotopePattern» (BrukerDaltonics, Германия).

Таблица 1. Метрологические характеристики методики определения натамицина в пищевых продуктах

\begin{tabular}{|c|c|c|c|c|c|c|}
\hline Брутто-формула & Аддукт & $\mathrm{t}_{\mathrm{R}}$, мин & $\mathrm{m} / \mathrm{z}$ & $\Delta, \mathrm{MлH}^{-1}$ & $\mathrm{c}_{\text {минн }}, \mathrm{Hг} / \Gamma$ & $\mathrm{c}_{\mathrm{H}}, \mathrm{Hг} / \Gamma$ \\
\hline $\mathrm{C}_{33} \mathrm{H}_{47} \mathrm{NO}_{13}$ & {$[\mathrm{M}+\mathrm{H}]^{+}$} & 3.2 & 666.3123 & 0.9 & 0.1 & 0.4 \\
\hline $\mathrm{C}_{33} \mathrm{H}_{47} \mathrm{NO}_{13}$ & {$[\mathrm{M}+\mathrm{Na}]^{+}$} & 3.2 & 688.2940 & 0.8 & 0.1 & 0.3 \\
\hline $\mathrm{C}_{33} \mathrm{H}_{47} \mathrm{NO}_{13}$ & {$[\mathrm{M}+\mathrm{K}]^{+}$} & 3.2 & 704.2679 & 0.8 & 0.1 & 0.3 \\
\hline
\end{tabular}

Идентификационными параметрами служили времена удерживания, точность массы иона $(\mathrm{m} / \mathrm{z})$ и $\mathrm{mSigma}$. Важный параметр $m$ Sigma - соответствие теоретического изотопного распределения практическому. Погрешность в определении масс ионов не превышала \pm 5 млн $^{-1}(n=3)$.

В условиях электрораспылительной ионизации натамицин образует протонированную форму $[\mathrm{M}+\mathrm{H}]^{+}$, а также аддукты с щелочными металлами $-[\mathrm{M}+\mathrm{Na}]^{+}$, $[\mathrm{M}+\mathrm{K}]^{+}$. На рис. 2 представлена масс-хроматограмма стандартного раствора натамицина в оптимальных условиях.

В табл. 1 приведены основные характеристики аддуктов натамицина, определяемых методом хромато-масс-спектрометрии. Следует отметить, что положительно заряженные производные натамицина имеют отличную друг от друга массу иона $(\mathrm{m} / z)$, что позволяет избежать ошибки при идентификации натамицина. А нали-

Большаков и др. / Сорбционные и хроматографические процессы. 2019. Т. 19. № 4 
чие пиков всех производных на хроматограмме пробы позволяет однозначно судить о наличии натамицина в анализируемом образце.
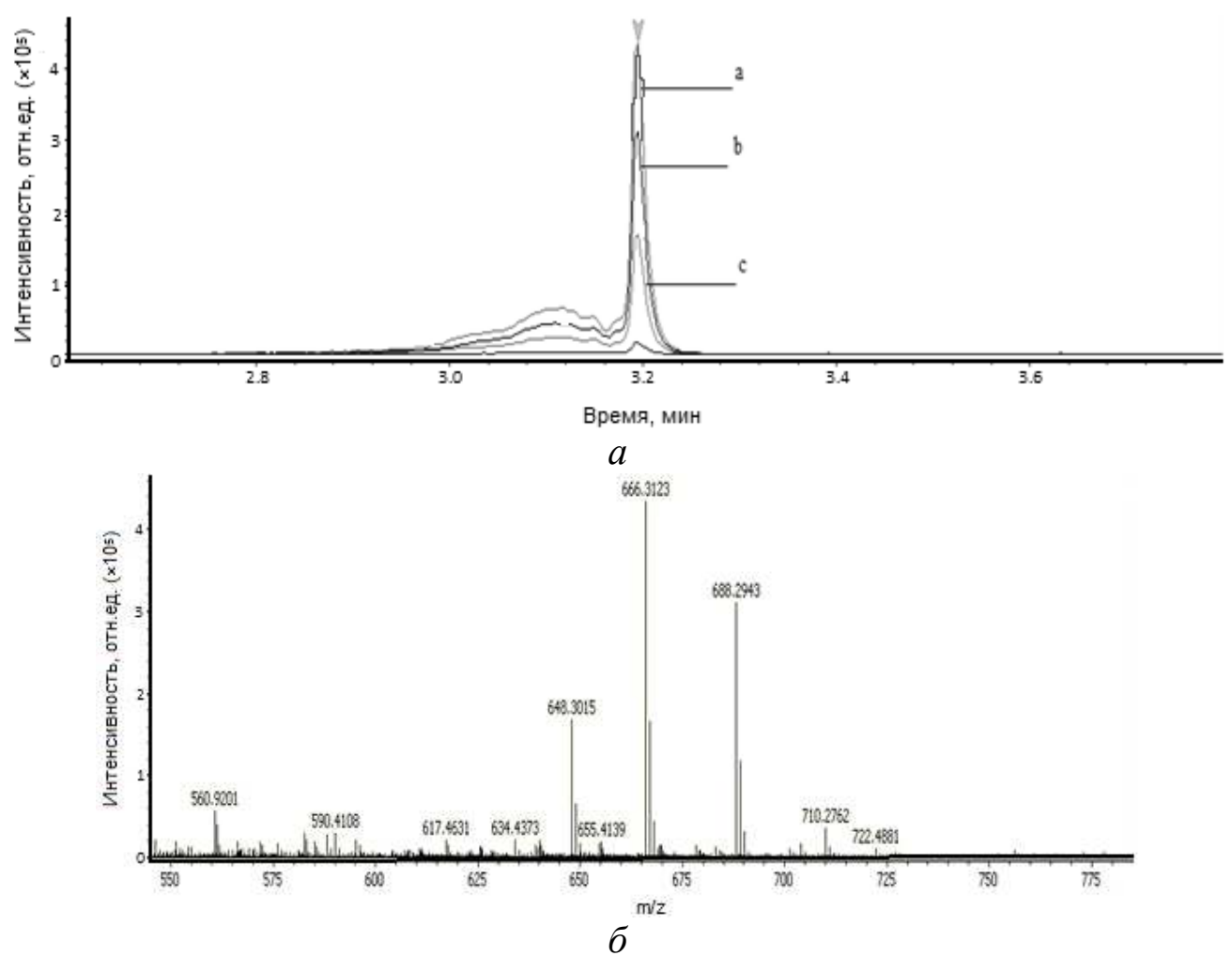

Рис. 2. Масс-хроматограмма аддуктов натамицина $(a)$ : $[\mathrm{M}+\mathrm{H}]^{+}(a),[\mathrm{M}+\mathrm{Na}]^{+}$ $(b),[\mathrm{M}+\mathrm{K}]^{+}(c)$ и их масс-спектр (б).

Определение натамицина проводили методом стандартной добавки. Данный метод имеет следующие преимущества перед методом внешнего стандарта (градуировочной характеристики). Во-первых, нет необходимости устанавливать степень извлечения аналитов, во-вторых, экономичность - требуется меньше дорогостоящих стандартных образцов сравнения и не требуется периодическая проверка стабильности градуировочных характеристик, в-третьих, повышается точность определения и, в-четвертых, нивелируется матричный эффект. Следует отметить, что прием однократной стандартной добавки действует в области линейной зависимости площади (высоты) хроматографического пика (пика $\mathrm{m} / z$ ) от концентрации аналита. Установлено, что линейная зависимость для рассматриваемого аналита наблюдается до с н до 100 нг/г.

Пределы обнаружения ( $\left.\mathrm{c}_{\text {мин }}\right)$ и пределы определения $\left(\mathrm{c}_{\mathrm{H}}\right)$ определяли при отношении сигнал/шум равном 3 и 10 для стандартного раствора аналитов. Диапазон определяемых содержаний составил 0.5-100 нг/г, предел обнаружения - 0.2 нг/г.

При выбранных ранее оптимальных условиях извлечения, разделения полученных экстрактов и масс-спектрометрического детектирования провели анализ нескольких образцов продуктов. В табл. 2 представлены результаты определения натамицина в вине, фруктовых соках и сыре. Из семи образцов пищевых продуктов в одной пробе фруктового нектара, в одной пробе вина и одной пробе сыра (корковый слой) обнаружен натамицин на уровне $15 \pm 3,18 \pm 3$ и $23 \pm 4$ нг/г соответственно. В трех образцах фруктового сока натамицин не обнаружен (менее 0.2 нг/г). Правильность выполнения анализа проверена методом «введено-найдено» с добавкой 
натамицина на уровне 50 нг/г (табл. 2). Примеры некоторых полученных хроматограмм приведены на рис. 3.

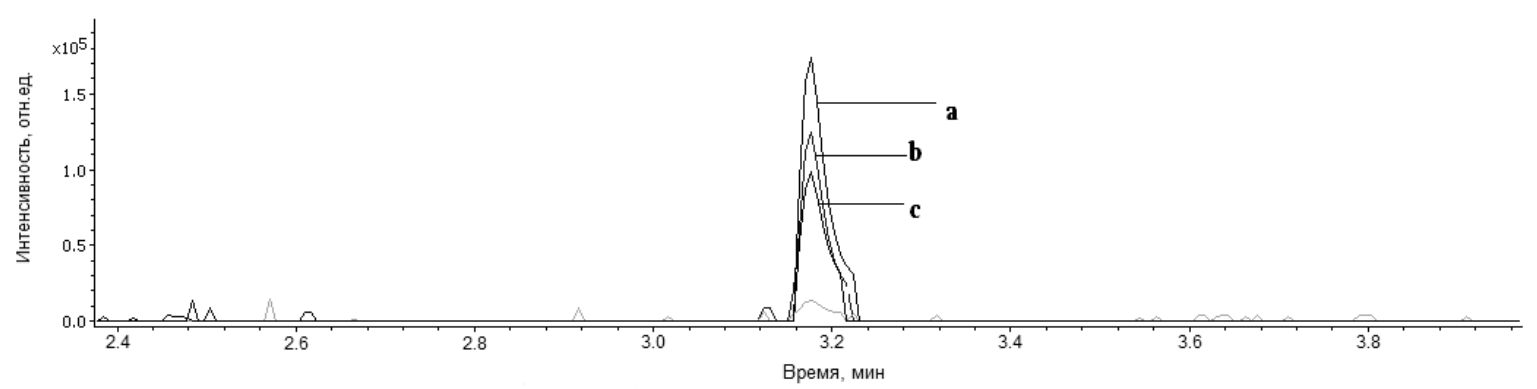

$a$

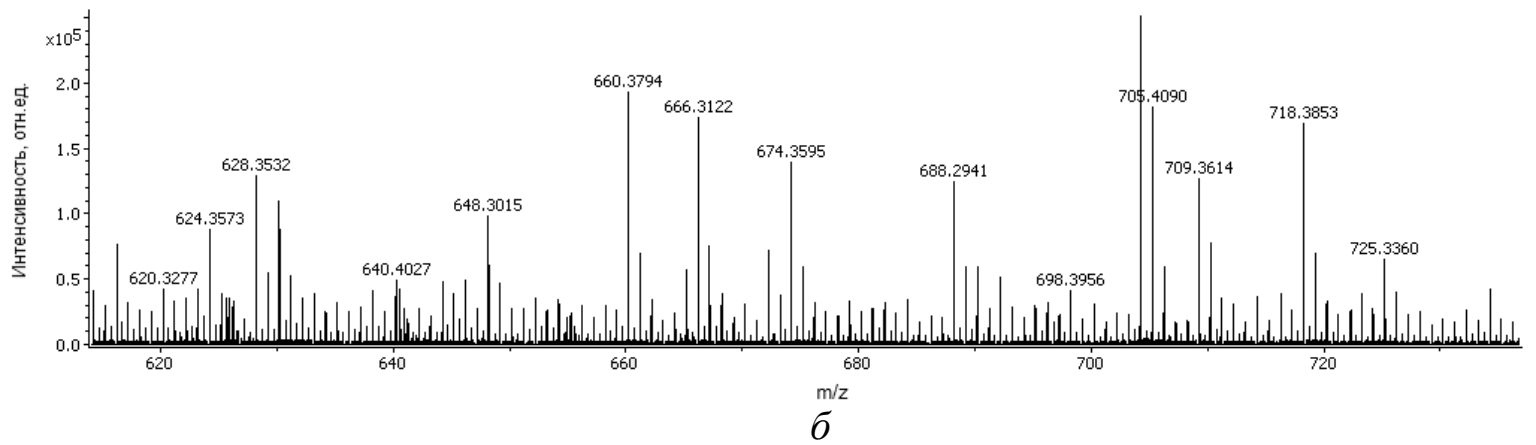

Рис. 3. Масс-хроматограмма аддуктов натамицина в экстракте яблочновиноградного нектара (образец № 2) $a: a-[\mathrm{M}+\mathrm{H}]^{+}, b-[\mathrm{M}+\mathrm{Na}]^{+}, c-[\mathrm{M}+\mathrm{K}]^{+}$ и их масс-спектр (б).

Таблица 2. Результаты определения натамицина в пищевых продуктах (n=3, $\mathrm{P}=0.95)$

\begin{tabular}{|c|c|}
\hline Матрица & $\begin{array}{c}\text { Найдено методом стандартной } \\
\text { добавки, нг/г }\left(s_{\mathrm{r}}\right)\end{array}$ \\
\hline Виноградный сок & не обнаружено \\
\hline Яблочно-виноградный нектар & $15 \pm 3(0.08)$ \\
\hline Виноградный нектар & не обнаружено \\
\hline Виноградный нектар (добавка 50 нг/г натамицина) & $49 \pm 7(0.09)$ \\
\hline Мультифруктовый сок & не обнаружено \\
\hline Яблочный сок & не обнаружено \\
\hline Вино (Италия) & $18 \pm 3(0.12)$ \\
\hline Вино (Италия) (добавка 50 нг/г натамицина) & $63 \pm 9(0.09)$ \\
\hline Сыр (корка) & $23 \pm 4(0.07)$ \\
\hline
\end{tabular}

\section{Заключение}

В работе предложена методика экспресс-идентификации и определения натамицина в пищевых продуктах методом ультравысокоэффективной жидкостной хроматографии/квадруполь-времяпролетной масс-спектрометрии высокого разрешения. Диапазон определяемых содержаний натамицина составил 0.5-100 нг/г, предел обнаружения - 0.2 нг/г при массе пробы 1.00 г. Для оценки количественного содержания натамицина в пищевых продуктах предложено использовать метод стандартной добавки. В сравнении с существующими подходами определения натамицина в пищевых продуктах предлагаемая методика отличается экспрессно- 
стью, простой подготовкой проб, не требующей использования большого количества токсичных растворителей или дорогостоящих концентрирующих патронов.

\section{Список литературы}

1. Малова И.О., Петрунин Д.Д. // Вестник дерматологии и венерологии. 2015. № 3. C 161-184.

2. Antimicrobials in food / edited by P. Michael Davidson, John N. Sofos, A.L. Branen. 3rd ed. p. cm. (Food science and technology; 143).

3. Абакумова А.А., Гугучкина Т.И., Антоненко М.В. // Виноградарство и виноделие. 2015. Т. 45. С. 116-117.

4. EFSA (2009)// The EFSA J. 2009. Vol. 7(12). pp. 1412-1437. doi: 10.2903/j.efsa.2009.1412.

5. Пищевой консервант Е235 Натамицин (пимарицин) http://findfood.ru/component /pishevoj-konservant-E235-natamicinpimaricin (дата обращения 29.07.2018).

6. Технический регламент Таможенного союза (ТР ТС 029/2012). Требования безопасности пищевых добавок, ароматизаторов и технологических вспомогательных средств (с изменениями на 18 сентября 2014 года): утв. Решениеv Совета Евразийской экономической комиссии от 20 июля 2012 г. № 58.308 c.

7. Технический регламент Таможенного союза (ТР ТС 021/2011). О безопасности пищевой продукции: утв. Решением Комиссии Таможенного союза от 09.12.2011 г. № $880.242 \mathrm{c}$.

8. Технический регламент Таможенного союза (ТР ТС 023/2011). Технический регламент на соковую продукцию из фруктов и овощей: утв. Решением Комиссии Таможенного союза от 09.12.2011 г. № 882. 56 с.

9. Chinese Standards for Food Additives China GB 2760-2015.

\section{References}

1. Malova I.O., Petrunin D.D., Vestnik dermatologii $i$ venerologii, 2015, No 3, pp. 161-184. (in Russian).

2. Antimicrobials in food / edited by P. Michael Davidson, John N. Sofos, A.L. Branen. 3rd ed. p. cm. - (Food science and technology; 143).

3. Abakumova A.A., Guguchkina T.I. Antonenko M.V., Vinogradarstvo $i$ vinodelie, 2015, Vol. 45, pp. 116-117. (in Russian).
10.Fahim N.K., Beheshti H.R., Feizy J., Janati S.S.F. // GIDA. 2012. Vol. 37 (3).pp. 127132.

11.Karalomlu O., Alkaya D.B. // Marmara Pharm. J. 2017. Vol. 21/2. pp. 355-360.

12.ГОСТ Р ИСО 9233-2-2011. Сыры и плавленые сыры. Определение содержания натамицина. Часть 2. Метод высокоэффективной жидкостной хроматографии. $\mathrm{M}$. Стандартинформ, 2013. 16 с.

13.Paseiro-Cerrato R., Otero-Pazos P., de Quiros A.R.-B., Sendon R. et al., // Food Control. 2013. Vol. 33. pp. 262-267. http://dx.doi.org/10.1016/j.foodcont.2013.03.0 06.

14.ISO 9233-1 | IDF 140-1: 2018 - Cheese, Cheese rind and processed cheese - Determination of natamycin content - Part 1: Molecular absorption spectrometric method for cheese rind.

15.Repizo L.M., Martinez L.D., Olsina R.A., Cerutti S. et al. // Anal. Bioanal. Chem. 2012. Vol. 402. pp. 965-973. DOI 10.1007/s00216011-5481-6.

16.Sun X., Li X., Wang P., Ma T., Huang W. Et al. // Food Chem. 2016. Vol. 194. pp. 928937.

http://dx.doi.org/10.1016/j.foodchem.2015.08. 116.

17.Антоненко М.В., Гугучкина Т.И., Гапоненко Ю.В., Абакумова А.А. // Плодоводство и виноградарство Юга России. 2015. № 34 (4). C. 143-152. URL: http://journalkubansad.ru/pdf/15/04/13.pdf. (дата обращения: 05.07.2018).

4. EFSA (2009). The EFSA Journal, 2009, Vol. 7(12), pp. 1412-1437. doi: 10.2903/j.efsa.2009.1412.

5. Pishchevoj konservant E235 Natamicin (pimaricin)

http://findfood.ru/component/pishevojkonservant-E235-natamicin-pimaricin (accessed 29 July 2018).

6. Tekhnicheskij reglament Tamozhennogo Soyuza (TR TS 029/2012). Trebovaniya bezo- 
pasnosti pishchevyh dobavok aromatizatorov $i$ tekhnologicheskih vspomogatelnyh sredstv. Technical Regulations of the Customs Union TR CU 029/2012. Safety requirements of food additives, aromatizers and technological supplements. 308 p. (in Russian).

7. Tekhnicheskij reglament Tamozhennogo Soyuza (TR TS 021/2011). O bezopasnosti pishchevoj produkcii. Technical Regulations of the Customs Union TR CU 021/2011. On safety of foodstuffs. 242 p. (in Russian).

8. Tekhnicheskij reglament Tamozhennogo Soyuza (TR TS 023/2011). Tekhnicheskij reglament na sokovuyu produkciyu iz fruktov $i$ ovoshchej. Technical Regulations of the Customs Union TR CU 023/2011. Technical regulations on fruit and vegetable juicy products. 56 p. (in Russian).

9. Chinese Standards for Food Additives China GB 2760-2015.

10. Fahim N.K., Beheshti H.R., Feizy J., Janati S.S.F., GIDA, 2012, Vol, 37 (3), pp. 127-132.

11. Karalomlu O., Alkaya D.B., Marmara Pharmaceutical Journal, 2017, Vol, 21/2, pp. 355-360.

12. GOST R ISO 9233-2-2011. Syry i plavlenye syry. Opredelenie soderzhaniya natamicina. Chast 2. Metod vysokoehffektivnoj zhid-

Большаков Дмитрий Сергеевич - к.х.н., старший научный сотрудник лаборатории химического анализа ФГБУ «Федеральный центр охраны здоровья животных» (ФГБУ «ВНИИЗЖ»), Владимир

Амелин Василий Григорьевич - д.х.н., професcop, профессор кафедры химии Владимирского государственного университета имени Александра Григорьевича и Николая Григорьевича Столетовых, ведущий научный сотрудник лаборатории химического анализа ФГБУ «Федеральный центр охраны здоровья животных» (ФГБУ «ВНИИЗЖ»), Владимир kostnoj hromatografii,M., Standartinform Publ., 2013. 16 p. (in Russian).

13. Paseiro-Cerrato R., Otero-Pazos P., de Quiros A.R.-B., Sendon R. et al., Food Control, 2013, Vol. 33, pp. 262-267. http://dx.doi.org/10.1016/j.foodcont.2013.03.0 06.

14. ISO 9233-1 | IDF 140-1: 2018 - Cheese, Cheese rind and processed cheese - Determination of natamycin content - Part 1: Molecular absorption spectrometric method for cheese rind.

15. Repizo L.M., Martinez L.D., Olsina R.A., Cerutti S. et al., Anal. Bioanal. Chem, 2012, Vol. 402, pp. 965-973. DOI 10.1007/s00216-011-5481-6.

16. Sun X., Li X., Wang P., Ma T., Huang W., Han S., Zhan J., Food Chemistry, 2016, Vol. 194, pp. 928-937. http://dx.doi.org/10.1016/j.foodchem.2015.08. 116.

17. Antonenko M.V., Guguchkina T.I., Gaponenko Yu.V., Abakumova A.A., Plodovodstvo i vinogradarstvo yuga rossii, 2015, No 34 (4), pp. 143-152. URL: http://journalkubansad.ru/pdf/15/04/13.pdf. (accessed 05 July 2018). (in Russian).

Bol'shakov Dmitry S. - candidate of science (chemistry), senior researcher, FGBI «Federal Centre for Animals Health» (ARRIAH), Vladimir, e-mail: bolshakov@arriah.ru

Amelin Vasily G. - doctor of science (chemistry), professor, professor of department of chemistry, Vladimir State University named after Alexander and Nikolay Stoletovs, leading researcher, FGBI «Federal Centre for Animals Health»(ARRIAH), Vladimir, e-mail: ame$\underline{\text { linvg@mail.ru }}$ 